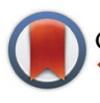

CrossMark

Cite this: Polym. Chem., 2017, 8, 890

\title{
Multi-stimuli responsive block copolymers as a smart release platform for a polypyridyl ruthenium complex $\dagger$
}

\author{
Michael Appold, ${ }^{a}$ Cristina Mari, ${ }^{b}$ Christina Lederle, ${ }^{c}$ Johannes Elbert, $\psi^{a}$ \\ Claudia Schmidt, ${ }^{\mathrm{d}}$ Ingo Ott, ${ }^{\mathrm{d}}$ Bernd Stühn, ${ }^{\mathrm{c}}$ Gilles Gasser*e and Markus Gallei*a
}

A variety of applications of amphiphilic block copolymers result from the control of their self-assembled structures. Herein, the synthesis and structure formation of block copolymers (BCPs) consisting of poly $(N, N-$ dimethylaminoethyl methacrylate) (PDMAEMA) as one segment and poly(methyl methacrylate) (PMMA) or a statistical copolymer (PDMAEMA-CO-PMMA) as a second segment, is described. The BCPs provide molar masses between $8.9 \mathrm{~kg} \mathrm{~mol}^{-1}$ and $35.6 \mathrm{~kg} \mathrm{~mol}^{-1}$ with low polydispersity index values, $\theta=$ 1.05-1.13. BCPs are synthesized via sequential anionic polymerization strategies while structure formation in water is investigated by dynamic light scattering (DLS) and transmission electron microscopy (TEM). The PDMAEMA-containing micelles in water are loaded with a Ru(॥) polypyridyl complex, i.e. [Ru(bipy) ${ }_{2}$-dppz7-hydroxymethyl] $\left[\mathrm{PF}_{6}\right]_{2}$ (bipy = 2,2'-bipyridine; $d p p z=$ dipyridophenazine), which was previously shown to act as a potential photosensitizer in photodynamic therapy (PDT). Successful loading of the BCP micelles is evidenced by TEM measurements after dialysis in water. Stimulus-responsive release of the $\mathrm{Ru}(I)$ complex from the BCP micelles is shown using ultrasound, change of $\mathrm{pH}$ or temperature as external triggers. The quantification and release profiles for the Ru(॥) complex are obtained by atomic absorption spectrometry (AAS). As a result, PDMAEMA-b-PMMA is not capable of releasing the Ru(॥) complex in a controlled manner after application of, for instance, ultrasound or temperature change as external triggers due to the shielding (stealth effect) of the BCP. On the contrary, micelles made of BCPs featuring PDMAEMA and PDMAEMA-CO-PMMA segments reveal excellent Ru(II) complex release profiles due to the tailored molecular composition of the underlying block segments as evidenced by temperature-dependent DLS and AAS measurements. Thus, these smart PDMAEMA-containing BCPs pave the way to a variety of applications for selective triggered release of small molecules.

Received 20th November 2016 Accepted 19th December 2016 DOI: $10.1039 / c 6 p y 02026 \mathrm{~g}$ rsc.li/polymers

\section{Introduction}

In the last decade stimuli-responsive polymers have proven their utility for a range of important applications. ${ }^{1-3}$ These types of polymers can be designed to feature certain chemical functionalities, which can be changed by invasive or non-invasive external triggers. They are capable of changing their conformation, solubility, or even of breaking or forming covalent bonds upon, for instance, a change of temperature or $\mathrm{pH}$ value, light irradiation, electrochemical stimuli or the presence of an electrical field, or combinations thereof. ${ }^{4-11}$ Polymerbased nanocontainers filled with payloads are promising systems for selective and gated transport in the fields of, e.g., biomedicine,$^{12-14}$ or anticorrosion. ${ }^{15,16}$ The preparation of block copolymers (BCPs), i.e., polymers consisting of two or more homogeneous polymer fragments that are covalently connected, feature the intrinsic capability for microphase separation yielding fascinating structures in the bulk state or 
in selective solvents. Encapsulation of molecules and oligomers has already been carried out in BCP micelles, vesicles or BCP capsules featuring even more complex substructures. ${ }^{17-20}$ For instance, multicompartment micelles were successfully prepared from triblock terpolymers and their fascinating selfassembled structures were studied in different media. ${ }^{21-24}$ Furthermore, in our first attempts, the selective release of two different payloads out of such complex BCP micelles featuring different compartments has been studied. ${ }^{25}$ Amongst all potential external triggers for selective release of payloads, thermal and $\mathrm{pH}$ value changes have been intensively investigated owing to their important role in physiological environments. Within the field of stimuli-responsive polymers, poly ( $N, N$-dimethylaminoethyl methacrylate) (PDMAEMA) is one major player due to its capability for rapid conformational changes during the change of temperature, $\mathrm{pH}$ (or the presence of $\mathrm{CO}_{2}$ ), and ionic strength. ${ }^{26-28}$ As another external trigger ultrasound is reported to be a potential stimulus for drug release from polymer micelles. ${ }^{29}$ The release can occur by diffusion of the payload or by degradation triggered by ultrasound. For example, the release of doxorubicin from Pluronic micelles could be achieved by insonation with low frequency ultrasound as reported by Husseini et al. ${ }^{30}$ or Marin et al. ${ }^{31}$

Like other cationic polymers, PDMAEMA is reported to be slightly cytotoxic and changes regarding the molecular architecture (for example copolymers with hydrophobic or hydrophilic monomers, branched system, chain ends) as well as the overall molar mass can significantly influence the cytotoxicity. ${ }^{32-35}$ Moreover, it is reported that the masking effects of PDMAEMA complexes play a crucial role in the cytotoxicity. ${ }^{34}$ To the best of our knowledge, the use of PDMAEMA as a multi-stimuli responsive polymer (and BCP thereof) has not been reported for the selective release of photodynamic therapy (PDT) photosensitizers. PDT is a medical method used to treat certain types of cancer and other skin conditions. ${ }^{36,37}$ A photodynamic effect is achieved due to the synergistic action of light, molecular oxygen normally present in tissues $\left({ }^{3} \mathrm{O}_{2}\right)$ and a photosensitizer. In detail, the first step is usually the intravenous administration of the photosensitizer to the patient. After 1-3 days, when the photosensitizer has localized in cancer cells, the photosensitizer is excited by light irradiation. The photosensitizer reaches its excited state, which has a triplet character. The excited photosensitizer can then interact with ${ }^{3} \mathrm{O}_{2}$. Upon energy transfer from the excited state of the photosensitizer to the ground state of ${ }^{3} \mathrm{O}_{2}$, a very reactive singlet oxygen species $\left({ }^{1} \mathrm{O}_{2}\right)$ is formed. This toxic form of oxygen is able to rapidly interact and damage the surrounding biological substrates, inducing a biological cascade of events that will eventually lead to cell death. PDT has a very localized toxic effect since ${ }^{1} \mathrm{O}_{2}$ is produced just at the site of light irradiation. Moreover, since its lifetime is very short in a biological environment (40 ns), ${ }^{1} \mathrm{O}_{2}$ will exert its toxic activity just in the proximity of its site of generation. ${ }^{38}$ The temporally and spatially defined formation of these toxic species is responsible for the low side effects of PDT compared to those that cancer patients have to usually go through during chemo- therapeutic treatment. The characteristics of the photosensitizer are of crucial importance for the medical outcomes. Nowadays, most of the clinically approved photosensitizers have a tetrapyrrolic structure (i.e. porphyrins, chlorins). ${ }^{39,40}$ This class of molecules is known for their very high ${ }^{1} \mathrm{O}_{2}$ production, long wavelength excitation and high cancer tissue accumulation. However, some drawbacks associated with these systems (i.e. non-trivial synthesis and purification, scarce water solubility, systemic accumulation) highlight the importance for the development of alternative photosensitizers. A great effort has been made in the last few decades to develop novel photosensitizers with a non-porphyrin based structure. Among the different types of compounds investigated, $\mathrm{Ru}(\mathrm{II})$ polypyridyl complexes were found to be extremely promising. ${ }^{37,41-45}$ Encouragingly, such a complex will soon enter into clinical trials as a photosensitizer for the treatment of non-muscle invasive bladder cancer. ${ }^{46}$ At our end, we have focused our attention, over the past few years, in the application of metal complexes as photosensitizers in PDT for the treatment of cancer ${ }^{47-49}$ and bacterial infections (aPDT) $)^{50}$ as well as in photoactivated chemotherapy (PACT) ${ }^{51,52}$ In particular, some $\mathrm{Ru}(\mathrm{II})$ polypyridyl complexes showed very promising results with, among others, an efficient cellular uptake and very high phototoxic indexes (PI, the ratio of dark toxicity over phototoxicity). ${ }^{37}$ Another important drawback of the tetrapyrrolic compounds used as PDT photosensitizers is related to their poor bioavailability. Porphyrins and porphyrin molecules are generally characterized by low water solubility and high lipophilicity, generating problems with regard to medicinal/ biological applications. To overcome these issues, the use of delivery systems was envisaged to improve the pharmacokinetic properties of the photosensitizers. As mentioned above for other payloads, a wide variety of carriers for photosensitizers have been applied, ranging from liposomes to micelles or organic or inorganic nanoparticles or polymers. ${ }^{53,54}$ As an example, FOSLIP $®$, a water-soluble liposomal formulation of the photosensitizer FOSCAN ${ }^{(}(m$-tetra(hydroxyphenyl) chlorin), a PDT photosensitizer approved in Europe) currently in preclinical tests, displayed rapid biodistribution and clearance from the bloodstream, together with selective tumor accumulation and reduced side effects. ${ }^{5-56}$ Worth mentioning, although not related to cancer therapy, is the case of Vysudine ${ }^{\circledR}$, in which the photosensitizer verteporfin is formulated as a green liposome powder. It was approved by the FDA as a photosensitizer for the treatment of age-related macular degeneration in 2000 and for the treatment of pathological myopia in $2001 .^{54}$ Of note, Lemercier et al. reported the encapsulation of two $\mathrm{Ru}(\mathrm{II})$-based photosensitizers in poly(D,Llactide-co-glycolide) nanoparticles. The free complexes were characterized by very high dark toxicity, which was strongly reduced upon encapsulation. ${ }^{57}$

Herein, we present the encapsulation of a $\mathrm{Ru}(\mathrm{II})$ polypyridyl complex, i.e., $\left[\mathrm{Ru}(\text { bipy })_{2}\right.$-dppz-7-hydroxymethyl $]\left[\mathrm{PF}_{6}\right]_{2}$ (bipy $=$ 2,2'-bipyridine; $\mathrm{dppz}=$ dipyridophenazine), which was previously shown to be a promising PDT photosensitizer by some of us. ${ }^{47}$ PDMAEMA-based block copolymers with either 
poly(methyl methacrylate) (PMMA) or a statistical copolymer (PMMA-Co-PDMAEMA) as a second block segment were prepared by sequential anionic polymerization strategies. The thermo-responsiveness of PDMAEMA-containing block copolymer (BCP) micelles was investigated in detail by temperaturedependent dynamic light scattering (DLS) measurements in water. The micelles were loaded with the $\mathrm{Ru}(\mathrm{II})$ polypyridyl complex and the release was triggered by ultrasound, $\mathrm{pH}$ and temperature variations. The $\mathrm{Ru}(\mathrm{II})$ complex-loaded and empty BCP micelles were characterized with respect to structure formation by transmission electron microscopy (TEM) and DLS, while the release profiles were obtained after dialysis via atomic absorption spectrometry (AAS).

\section{Results and discussion}

\section{Polymer synthesis and characterization}

For encapsulation of $\left[\mathrm{Ru}(\text { bipy })_{2}\right.$-dppz-7-hydroxymethyl $]\left[\mathrm{PF}_{6}\right]_{2}$, block copolymers consisting of PMMA and poly $(N, N$-dimethylaminoethyl methacrylate) (PDMAEMA) were investigated. The stimuli-responsive block copolymers PMMA- $b$-PDMAEMA 4 were synthesized via anionic polymerization in THF with diphenylhexyllithium (DPHLi) as an initiator - prepared by the nucleophilic addition of $n$-butyl lithium to 1,1-diphenylethylene (DPE) - at low temperatures (see the Experimental section). The synthesis is depicted in Fig. 1 (top).

The corresponding PMMA- $b$-PDMAEMA BCPs 4 were analyzed by size exclusion chromatography (SEC) in dimethylformamide (DMF) and ${ }^{1} \mathrm{H}$ NMR spectroscopy. Exemplarily, the results on the sequential anionic polymerization of DMAEMA

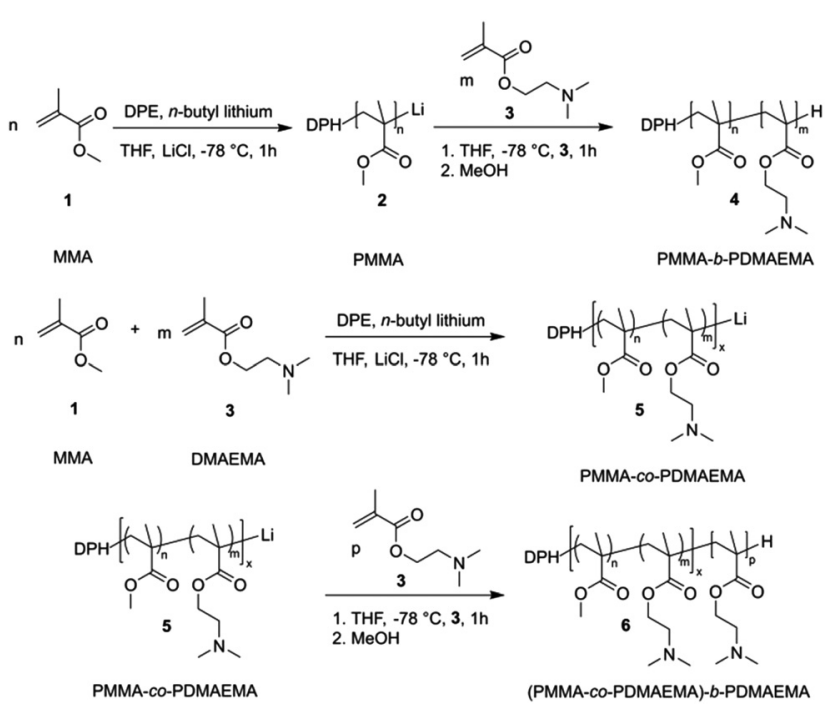

Fig. 1 Top: Anionic block copolymerization of methyl methacrylate 1 (MMA) and $N, N$-dimethylaminoethyl methacrylate 3 (DMAEMA) in THF in the presence of $\mathrm{LiCl}$ at low temperature to yield PMMA-b-PDMAEMA 4. Bottom: MMA and DMAEMA were copolymerized by means of anionic polymerization followed by the addition of DMAEMA to generate the corresponding PMMA-Co-PDMAEMA- $b$-PDMAEMA 6. and MMA for the preparation of $\mathrm{PMMA}_{54}-b$-PDMAEMA 95 are given. In Fig. 2, the molar mass distribution of the PMMA macro precursor (black) and the corresponding PMMA- $b$ PDMAEMA is shown, evidencing the successful BCP formation without significant termination of the PMMA anionic macro initiator. Additionally, the corresponding ${ }^{1} \mathrm{H}$ NMR spectrum for the final BCP with signal assignments is given in Fig. 2 (bottom).

All obtained data for the PMMA homopolymers and block copolymers - with PDMAEMA or PDMAEMA-co-PMMA as a second block segment - investigated in this study comprising $M_{\mathrm{n}}, M_{\mathrm{w}}$, and $\doteq$ are compiled in Table 1 .

As described in the ensuing sections, structure formation in water as well as capability for the stimuli-responsive release of payloads were initially carried out with PMMA- $b$-PDMAEMA BCPs. Based on these results, the usability of PDMAEMA BCPs having a PDMAMEA-co-PMMA segment was taken into account. For this purpose, the mixtures of MMA and DMAEMA were used prior to the formation of the PDMAEMA block to yield polymer 6 (see the Experimental section and Fig. 1). An exemplary molar mass distribution of $\left(\mathrm{PMMA}_{13}-\mathrm{Co}\right.$ PDMAEMA $_{22}$ )- $b$-PDMAEMA ${ }_{132}$ is given as Fig. $\mathrm{S} 1$ in the ESI, $\dagger$ while the corresponding ${ }^{1} \mathrm{H}$ NMR spectrum is given as Fig. S2.† Data on SEC and ${ }^{1} \mathrm{H}$ NMR spectroscopy proved the
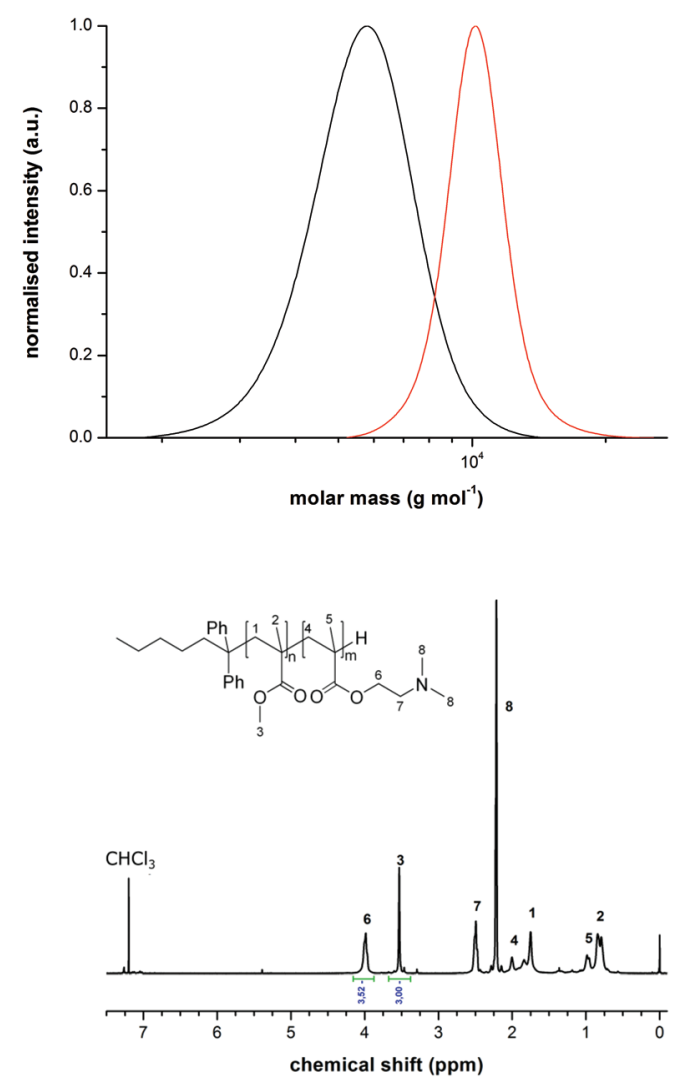

Fig. 2 Molar mass distributions (top) obtained by SEC measurements vs. PMMA standards in DMF obtained for the $\mathrm{PMMA}_{54}$ precursor (black line) and $\mathrm{PMMA}_{54}-b-\mathrm{PDMAEMA}_{95}$ (red line). The ${ }^{1} \mathrm{H}$ NMR spectrum of $\mathrm{PMMA}_{54}$-b-PDMAEMA 95 in $\mathrm{CDCl}_{3}$ (bottom). 
Table 1 Characterization data on homopolymers and block copolymers investigated in this study

\begin{tabular}{|c|c|c|c|}
\hline Polymer & $\begin{array}{l}M_{\mathrm{n}}{ }^{a} \\
\left(\mathrm{~kg} \mathrm{~mol}{ }^{-1}\right)\end{array}$ & $\begin{array}{l}M_{\mathrm{w}}{ }^{a} \\
\left(\mathrm{~kg} \mathrm{~mol}{ }^{-1}\right)\end{array}$ & $D$ \\
\hline $\mathrm{PMMA}_{63}{ }^{a}$ & 6.3 & 6.4 & $1 .($ \\
\hline PMMA $_{63}-b-$ PDMAEMA $_{25}{ }^{a}$ & 8.5 & 8.9 & 1.1 \\
\hline $\mathrm{PMMA}_{54}{ }^{a}$ & 5.4 & 5.8 & 1.0 \\
\hline PMMA $_{54}-b$-PDMAEMA ${ }_{95}{ }^{a}$ & 10.0 & 10.4 & 1.0 \\
\hline $\mathrm{PMMA}_{19}-\mathrm{co}$-PDMAEMA ${ }_{22}{ }^{b}$ & 5.4 & 6.0 & 1.1 \\
\hline $\begin{array}{l}\left(\mathrm{PMMA}_{19}-\mathrm{Co}-\mathrm{PDMAEMA}_{22}\right)-b- \\
\text { PDMAEMA }_{191}{ }^{-}\end{array}$ & 31.8 & 35.8 & 1.1 \\
\hline $\mathrm{PMMA}_{13}-$-Co-PDMAEMA $22{ }^{b}$ & 4.7 & 5.3 & \\
\hline$\left(\mathrm{PMMA}_{13}-\mathrm{Co}-\mathrm{PDMAEMA}_{22}\right)-b-$ & 26.9 & 29.6 & 1.1 \\
\hline
\end{tabular}

PDMAEMA $_{132} b$

${ }^{a}$ Molecular weight determined by SEC in $\mathrm{kg} \mathrm{mol}^{-1}$ (PMMA standards, DMF). ${ }^{b}$ Molecular weight in $\mathrm{kg} \mathrm{mol}^{-1}$ determined by SEC in DMF and the relative composition for PDMAEMA and PMMA determined by ${ }^{1} \mathrm{H}$ NMR spectroscopy in $\mathrm{CDCl}_{3}$.

successful synthesis of the PDMAEMA-containing BCP (see also Table 1), which will be investigated in the following sections. Additionally, thermal phase behavior of the BCPs was investigated by DSC measurements revealing glass transition temperatures of approx. $30^{\circ} \mathrm{C}$ and $90-100{ }^{\circ} \mathrm{C}$ which could be assigned to PDMAEMA or PDMAEMA-co-PMMA segments, respectively. ${ }^{58,59}$ All data on SEC, NMR spectroscopy and DSC measurements for the investigated BCPs and BCPs with a statistical segment are given in the ESI as Fig. S3-S10. $\dagger$

As the thermo-responsiveness of the PDMAEMA-containing segment was of major interest, the ratio of MMA and DMAEMA was varied in order to tailor the LCSTs. For this purpose, the weight content of MMA was varied from $4.5 \mathrm{wt} \%$, over $17 \mathrm{wt} \%$ to $26.9 \mathrm{wt} \%$ and UV-Vis spectroscopy measurements were carried out to determine the LCST (Fig. S11†). As can be concluded from these experiments, the LCST for the statistical PDMAEMA-co-PMMA could be tailored in the range of $17{ }^{\circ} \mathrm{C}$ to approximately $35^{\circ} \mathrm{C}$. A rough trend for the relationship of the LCST with the increasing MMA content is given as Fig. S12 in the ESI. $\dagger$ All data on glass transition temperatures and LCSTs for the investigated BCPs in this study are compiled in Table $\mathrm{S} 1$ of the ESI. $\dagger$

\section{Structure formation of PDMAEMA-containing block copolymers in water}

Before the stimulus-induced release of a PDT agent payload is studied in more detail, structure formation of the PDMAEMAbased diblock copolymers in a block-selective solvent for PDMAEMA, i.e. water, was investigated. In general, due to their amphiphilic nature, the BCPs are capable of self-assembling into micelles in aqueous solution. ${ }^{60-62}$ We investigated the micellation in the presence or absence of $\left[\mathrm{Ru}(\mathrm{bipy})_{2}\right.$-dppz-7hydroxymethyl $]\left[\mathrm{PF}_{6}\right]_{2}$ complex 7 as depicted in Scheme 1 and as described in the Experimental section. In brief, BCPs (and complex 7) were diluted in a small amount of acetone followed by dropwise addition of water (Milli-Q) and dialysis. In Fig. S13, $\dagger$ a photograph of the BCP micelles in water is

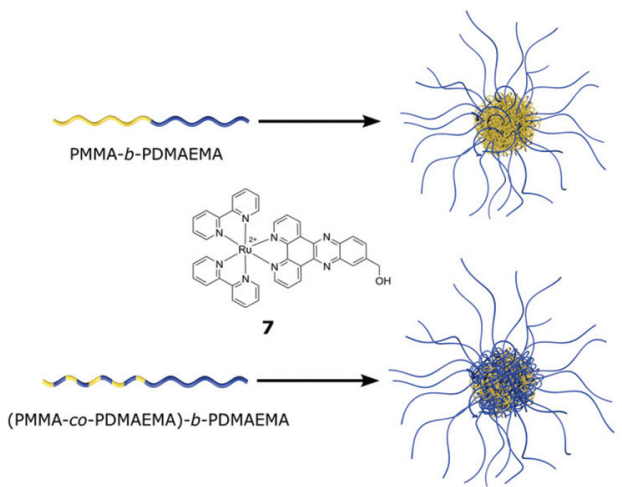

Scheme 1 Simplified illustration of BCP micelle formation for PMMA$b$-PDMAEMA and (PMMA-Co-PDMAEMA)- $b$-PDMAEMA BCPs in water. The micelles were directly compared by using TEM measurements in the presence of $\left[\mathrm{Ru}\left(\text { bipy) }{ }_{2} \text {-dppz-7-hydroxymethyl][PF }\right]_{2}\right.$ complex 7 (see the text).

given. In the case of BCP micelles loaded with $\left[\mathrm{Ru}(\mathrm{bipy})_{2}\right.$-dppz7-hydroxymethyl] $\left[\mathrm{PF}_{6}\right]_{2}$ complex 7 , a slightly yellow to orange color could be observed after dialysis, while in the case of the unloaded micelles, no turbidity or color was observed. This was a first hint that entrapment of $\mathrm{Ru}(\mathrm{II})$ complex 7 was successful.

In order to confirm these findings, comparative TEM measurements of the empty BCP micelles, which were formed by the polymer $\left(\mathrm{PMMA}_{13}-\mathrm{Co}\right.$-PDMAEMA 22$)-b$-PDMAEMA ${ }_{132}$, and BCP micelles loaded with $\mathrm{Ru}(\mathrm{II})$ complex 7 were carried out (Fig. 3). For TEM measurements, one drop of the resulting micellar solution was deposited on a carbon-coated copper grid, and the solvent was removed in vacuo. Interestingly, the empty BCP micelles could not be observed during TEM measurements, potentially due to the weak electron contrast of the micelles compared to the carbon background of the coated TEM copper grids. However, after staining with iodine the empty micelles of the statistical block copolymer $\left(\mathrm{PMMA}_{13}-\mathrm{CO}\right.$ -

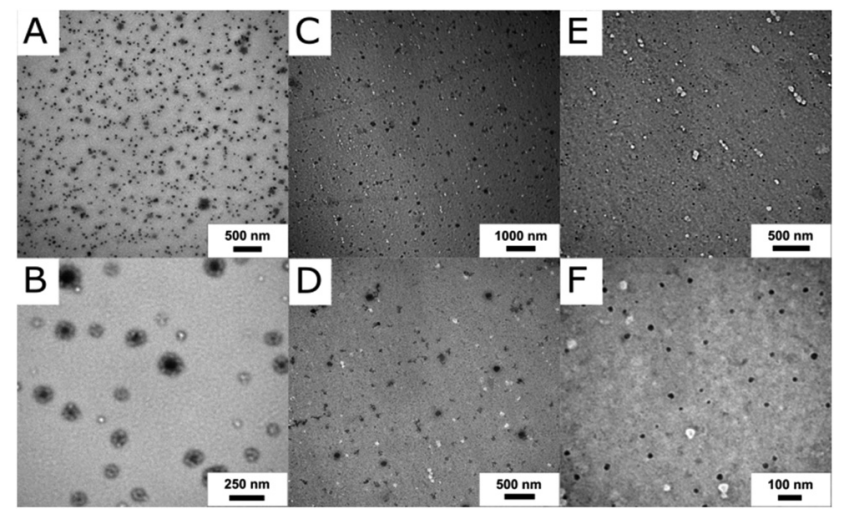

Fig. 3 TEM images of Ru(II) complex 7 loaded $B C P$ micelles $P_{M M A_{54}-b-}$ PDMAEMA $_{95}$ (A and B), (PMMA 19 -Co-PDMAEMA 22 )- $b$-PDMAEMA ${ }_{191}$ $(C$ and $\mathrm{D})$ and $\left(\mathrm{PMMA}_{13}-\mathrm{CO}-\mathrm{PDMAEMA}_{22}\right)-b-\mathrm{PDMAEMA}_{132}$ ( $\mathrm{E}$ and $\mathrm{F}$ ) obtained after dialysis, drop-casting on carbon-coated copper grids and without staining. 
PDMAEMA $_{22}$ )- $b$-PDMAEMA ${ }_{132}$, which will be important for the thorough DLS measurements in the ensuing section, could be observed using TEM (Fig. S14 $\dagger$ ). The average diameter of the stained spherical micelles was determined to be 8-9 $\mathrm{nm}$. Compared to this, the corresponding TEM images for the loaded micelles of $\mathrm{PMMA}_{54}-b$-PDMAEMA ${ }_{95}$ (Fig. 3A and B) and both BCPs featuring a statistical PDMAEMA-co-PMMA as the second block segment, i.e., ( $\left.\mathrm{PMMA}_{19}-\mathrm{co}-\mathrm{PDMAEMA}_{22}\right)-b$ PDMAEMA $_{191}$ (Fig. 3C and D) and (PMMA ${ }_{13}-\mathrm{Co}-\mathrm{PDMAEMA}_{22}$ )$b$-PDMAEMA 132 (Fig. $3 \mathrm{E}$ and $\mathrm{F}$ ) are shown. In this case, for the loaded BCP micelles, no further treatment was necessary to increase the contrast due to the high electron density of $\mathrm{Ru}$ (II) complex 7.

The TEM images for $\mathrm{PMMA}_{54}-b$-PDMAEMA ${ }_{95}$ clearly revealed a core-shell structure for the BCP micelles. The dark appearing core was attributed to the presence of $\mathrm{Ru}(\mathrm{II})$ complex 7 (Fig. 3A and B). Compared to this, both BCPs with a statistical PDMAEMA-co-PMMA segment did not feature an observable core-shell structure and homogeneous micelles could be observed (Fig. 3C-F). Summarizing the results of TEM measurements on the loaded BCP micelles, the herein investigated PDMAEMA-containing BCPs are capable of encapsulating the photosensitizer in the interior of the micellar structure in an aqueous environment. Before we turn to the Ru(II) complex 7 release, temperature-dependent dynamic light scattering (DLS) experiments are performed and discussed below.

Thermoresponsive behaviour of BCP micelles by dynamic light scattering (DLS) measurements

The temperature-responsiveness of the BCP micelles in water was followed using temperature-dependent dynamic light scattering (DLS) measurements. It is worth mentioning that the focus was on investigating the polymer $\left(\mathrm{PMMA}_{13}-\mathrm{CO}\right.$ PDMAEMA $_{22}$ )- $b$-PDMAEMA ${ }_{132}$ as the model system, which has the highest ratio of PDMAEMA in the statistical block segment (as compared for all polymers in Table S2 $\dagger$ ) in this study. As will be described in the ensuing section, the polymer $\mathrm{PMMA}_{54}{ }^{-}$ $b$-PDMAEMA ${ }_{95}$ was not able to release a significant amount of $\mathrm{Ru}$ (II) complex 7 after 90 min of ultrasound, while PMMA $_{13}-\mathrm{Co}$ PDMAEMA $_{22}$ )- $b$-PDMAEMA ${ }_{132}$ featured a reasonable leakage of the $\mathrm{Ru}(\mathrm{II})$ complex already at room temperature. Compared to this, the polymer $\left(\mathrm{PMMA}_{19}\right.$-co-PDMAEMA 22$)$ - $b$-PDMAEMA 191 having a lower ratio of PDMAEMA in the statistical block segment (as compared for all polymers in Table S2 $\dagger$ ) featured the best properties with respect to the payload release applying external triggers, i.e., by applying ultrasound, changing the $\mathrm{pH}$ value and temperature variation. We started studying the thermo-responsive behaviour of $\left(\mathrm{PMMA}_{13}-\mathrm{co}\right.$-PDMAEMA 22 )- $b$ PDMAEMA $_{132}$ in more detail in order to clarify the leakage occurring already at room temperature. All detailed measurement conditions for the DLS experiments are given in Table S3 of the ESI. $\dagger$ Fig. 4 illustrates two examples of the measured intensity autocorrelation functions for the micelles at $20{ }^{\circ} \mathrm{C}$ and $6^{\circ} \mathrm{C}$. Note that the decay of the correlation functions shows clearly two steps. The faster process corresponds to the translation dynamics of uniform micelles formed from
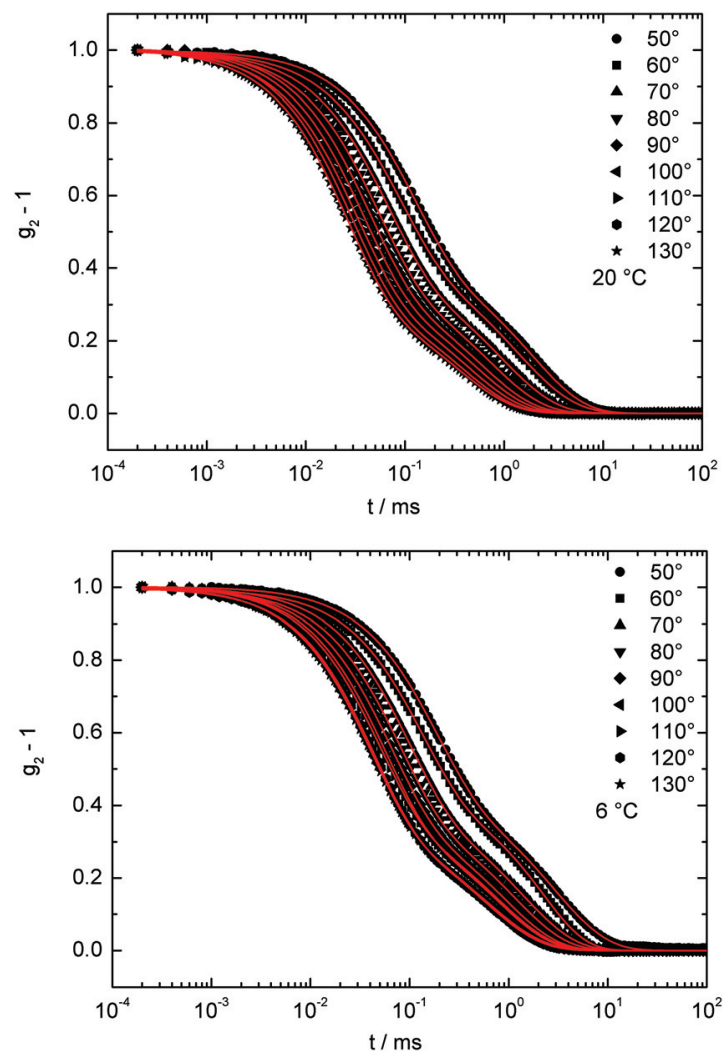

Fig. 4 Intensity autocorrelation functions for $B C P$ micelles formed from $\left(\mathrm{PMMA}_{13}-\mathrm{CO}-\mathrm{PDMAEMA} 22\right)-b$-PDMAEMA $A_{132}$ in water at $2 \theta$ : $50^{\circ}-130^{\circ}$, measured at $20^{\circ} \mathrm{C}$ (top) and $6{ }^{\circ} \mathrm{C}$ (bottom). The solid lines represent a fit using a squared sum of two exponential decays.

$\left(\mathrm{PMMA}_{13}\right.$-co-PDMAEMA 2 )- $b$-PDMAEMA 132 chains in water, while the slower process belongs to the dynamics of some micellar aggregates. For a direct comparison, the drop-cast and dried micelles were investigated by TEM as already described in the section above (Fig. S13†). From the TEM images it was concluded that the spherical micelles featured an average diameter of approximately 8-9 nm. For DLS measurements, both processes are well separated on the time scale and it is therefore possible to analyse these two dynamics in detail. To analyse the temperature-responsiveness of the hydrodynamic radii of the micelles it is necessary to calculate the correlation time $\tau$ for every process.

The intensity autocorrelation functions can be described by a squared sum of two exponential decays (see Fig. 4):

$$
g_{2}-1=\left(A_{1} \exp \left(-\left(t / \tau_{1}\right)^{\beta 1}\right)+A_{2} \exp \left(-\left(t / \tau_{2}\right)^{\beta 2}\right)\right)^{2} .
$$

$A_{1}$ and $A_{2}$ describe the amplitudes of the processes, with $A_{1}+A_{2}=1, \tau_{1}$ and $\tau_{2}$ are the correlation times and $\beta 1$ and $\beta 2$ are stretching parameters. These parameters correspond to the polydispersity of the micelles and aggregates. For example if $\beta$ is equal to 1 , the micelles are ideally monodisperse. This is the case for the faster process which can be assigned to the uniform $\left(\mathrm{PMMA}_{13}\right.$-co-PDMAEMA 22$)$ - $b$-PDMAEMA ${ }_{132}$ micelles. 
Compared to this, the micellar aggregates have a stretching parameter $0.7<\beta<0.85$ independent of $T$. The correlation time $\tau$ is related to the translational diffusion coefficient $D$ by $D=1 /\left(<\tau>q^{2}\right)$. The scattering vector $q$ can be calculated by $q=$ $4 \pi n \sin (\theta) / \lambda$. In our case $n$ is the refractive index of water and $2 \theta$ is the scattering angle. The averaged correlation time is $<\tau>=\tau / \beta \times \Gamma(1 / \beta)$, while $\Gamma$ is the gamma function.

The expected linear variation of $1 /<\tau>$ with $q^{2}$ was nicely fulfilled by our data (Fig. 5 and S15†), for both motions and at every measured temperature. By using the Stokes-Einstein relation, a hydrodynamic radius $R_{\mathrm{h}}=k_{\mathrm{B}} T / 6 \eta \pi D$ can be calculated, with $k_{\mathrm{B}}, T$, and $\eta$ as the Boltzmann constant, the absolute temperature, and the solvent viscosity at the used temperature, respectively. Note that the hydrodynamic radius of the uniform PDMAEMA-containing micelles is a factor 30 smaller than that of the aggregates at $20^{\circ} \mathrm{C}$ (Fig. 5 and $\mathrm{S} 14 \dagger$ ).

To investigate the temperature-responsiveness of the $\mathrm{BCP}$ micelles formed from $\left(\mathrm{PMMA}_{13}-\right.$ - 0 -PDMAEMA 22 )- $b$-PDMAEMA ${ }_{132}$, the temperature was varied between $50{ }^{\circ} \mathrm{C}$ and $6{ }^{\circ} \mathrm{C}$. Fig. $\mathrm{S} 16^{\dagger}$ shows the behaviour of the inverse relaxation times scaled with the temperature dependent viscosity of the water ${ }^{63}$ and the temperature versus the squared scattering vector for different temperatures. The hydrodynamic radius of the aggregates at $40{ }^{\circ} \mathrm{C}$ was approximately $117 \pm 40 \mathrm{~nm}$ (Fig. S15, $\dagger$ left). Compared to this, the uniform spherical micelles revealed a value of $R_{\mathrm{h}}$ of $4 \pm 0.1 \mathrm{~nm}$. When the solution was cooled down to $20{ }^{\circ} \mathrm{C}$, the hydrodynamic radius, $R_{\mathrm{h}}$, continuously increased by $10 \%$. For temperatures below $20{ }^{\circ} \mathrm{C}$ and above $10{ }^{\circ} \mathrm{C}$ the radius was nearly constant and $\sim 18 \%$ larger than before at $40{ }^{\circ} \mathrm{C}$. At $6{ }^{\circ} \mathrm{C}$ the radius of the aggregates shrank again (Fig. $\mathrm{S} 5 \dagger$ ). Although this repeated shrinkage of the aggregates could not be fully interpreted yet, for the proposed release studies the presence of a significant increase of the uniform micelles while decreasing the temperature below $30-35{ }^{\circ} \mathrm{C}$ is of utmost importance. It is noteworthy that for temperatures above $40{ }^{\circ} \mathrm{C}$, the radius of the micelles increased dramatically and the polymers precipitated. Almost the same temperature-

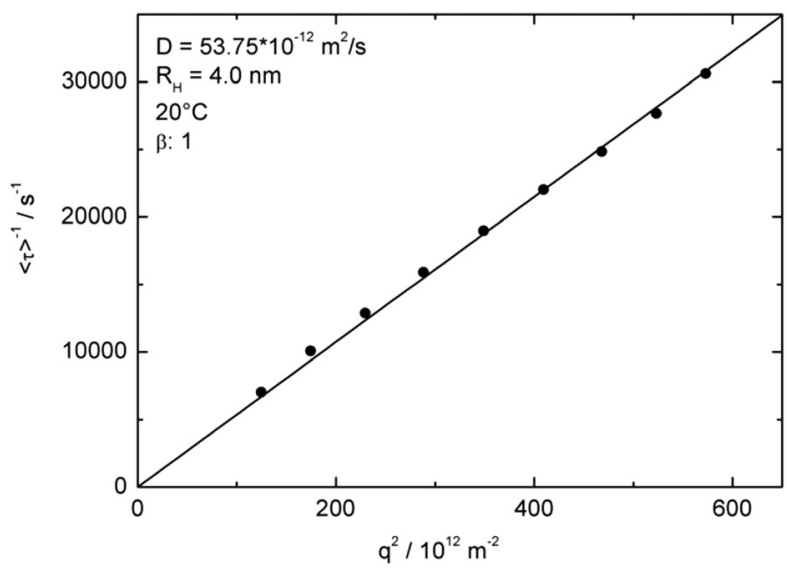

Fig. $5 q^{2}$ dependence of inverse relaxation times to determine the diffusion coefficient and the resulting hydrodynamic radii for the fast process of the uniform micelle motions measured at $20^{\circ} \mathrm{C}$.

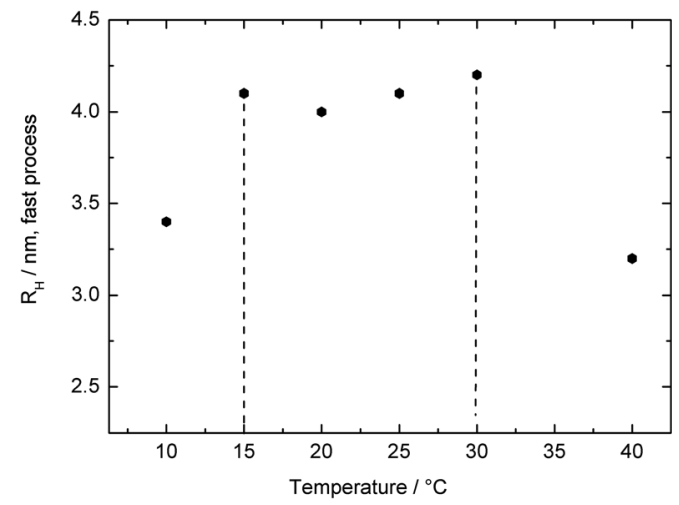

Fig. 6 Temperature dependence of the hydrodynamic radii of the $B C P$ micelles in water for the polymer $\left(\mathrm{PMMA}_{13}-\mathrm{CO}-\mathrm{PDMAEMA}_{22}\right)-b-$ PDMAEMA $_{132}$.

responsiveness of the micelles was found for the micellar aggregates. The chain radius grew by a factor of approximately $30 \%$, when cooling the temperature from $40{ }^{\circ} \mathrm{C}$ to $30^{\circ} \mathrm{C}$. After that growth, the radius was constant until $15{ }^{\circ} \mathrm{C}$ and shrank again at lower temperatures. Fig. 6 shows and summarizes the temperature behaviour of the hydrodynamic radii for the fast process (BCP micelles) while the thermo-responsiveness of the aggregates is given as Fig. S17. $\dagger$ The observed temperature variation of the hydrodynamic radii was fully reversible.

As a summary of the DLS results, it can be concluded from Fig. 6 and S16 $\uparrow$ that the BCP aggregates as well as the uniform BCP micelles grow and shrink as a function of temperature. At temperatures above $20^{\circ} \mathrm{C}$ there is a change in the solubility of polymers in water because it is above the first lower critical solution temperature. Between $20{ }^{\circ} \mathrm{C}$ and $10^{\circ} \mathrm{C}$ it is a homogeneous solution and the polymer chains and the micelles are capable of swelling in water. This proves the suitability of the BCP micelle for further investigation as a thermo-responsive release platform, which will be described in the ensuing section.

\section{Stimuli-responsive release of the Ru(II) complex by external triggers}

The stimuli-induced release of $\left[\mathrm{Ru}(\text { bipy })_{2}\right.$-dppz-7-hydroxymethyl $]\left[\mathrm{PF}_{6}\right]_{2}$ was determined by atomic absorption spectrometry (AAS) for the purified micelles (see the Instrumentation section for detailed sample treatment). The micelles were loaded with the $\mathrm{Ru}(\mathrm{II})$ complex as already described above. Importantly, dialysis of the loaded micelles was carried out using the dialysis membranes Spectra/Por ${ }^{\circledR}$ Biotech CE. In our first attempts with other dialysis membranes, there was an observable color change of the dialysis tube due to the interaction of the released Ru(II) complex with the membrane material. Three different external triggers were applied in order to study the release capabilities of the herein investigated PDMAEMA-based BCPs. In Scheme S1 of the ESI, $\dagger$ the simplified mechanism for releasing the encapsulated $\mathrm{Ru}(\mathrm{II})$ complex is given. In our first attempts, the BCPs PMMA- 
$b$-PDMAEMA were used for encapsulation. As shown in Fig. 3A and $\mathrm{B}$ in the previous section, the incorporation could be confirmed by TEM measurements. However, it turned out that, even with using ultrasound for about $45 \mathrm{~min}$, the BCP micelles did not release a detectable amount of ruthenium species (Fig. S18†). Only after a prolonged ultrasound time of $90 \mathrm{~min}$, a tiny amount of $\mathrm{Ru}(\mathrm{II})$ complex was released to the aqueous environment. It has to be mentioned that the detection limit of the AAS setup was about $0.5 \mu \mathrm{M}$ ruthenium.

In order to study the influence on release properties, the molecular compositions of the BCPs were changed and MMA was copolymerized with DMAEMA in order to obtain (PMMAco-PDMAEMA)- $b$-PDMAEMA. For simplification, we renamed $\left(\mathrm{PMMA}_{19}-c o\right.$-PDMAEMA 22$)-b$-PDMAEMA 191 to Copo1 and $\left(\mathrm{PMMA}_{13}-c o\right.$-PDMAEMA 22$)-b$-PDMAEMA 132 to Copo2. As a result, Copo2, which has a higher content of DMAEMA moieties in the copolymer segment, already showed a significant release of the $\mathrm{Ru}(\mathrm{II})$ complex at room temperature without an external stimulus (Fig. 7A, blank test). The explanation for this behaviour is as follows: Copo2 features a second LCST (compared to the pure PDMAEMA segment) approximately at room temperature. Therefore, a release of the $\mathrm{Ru}(\mathrm{II})$ complex
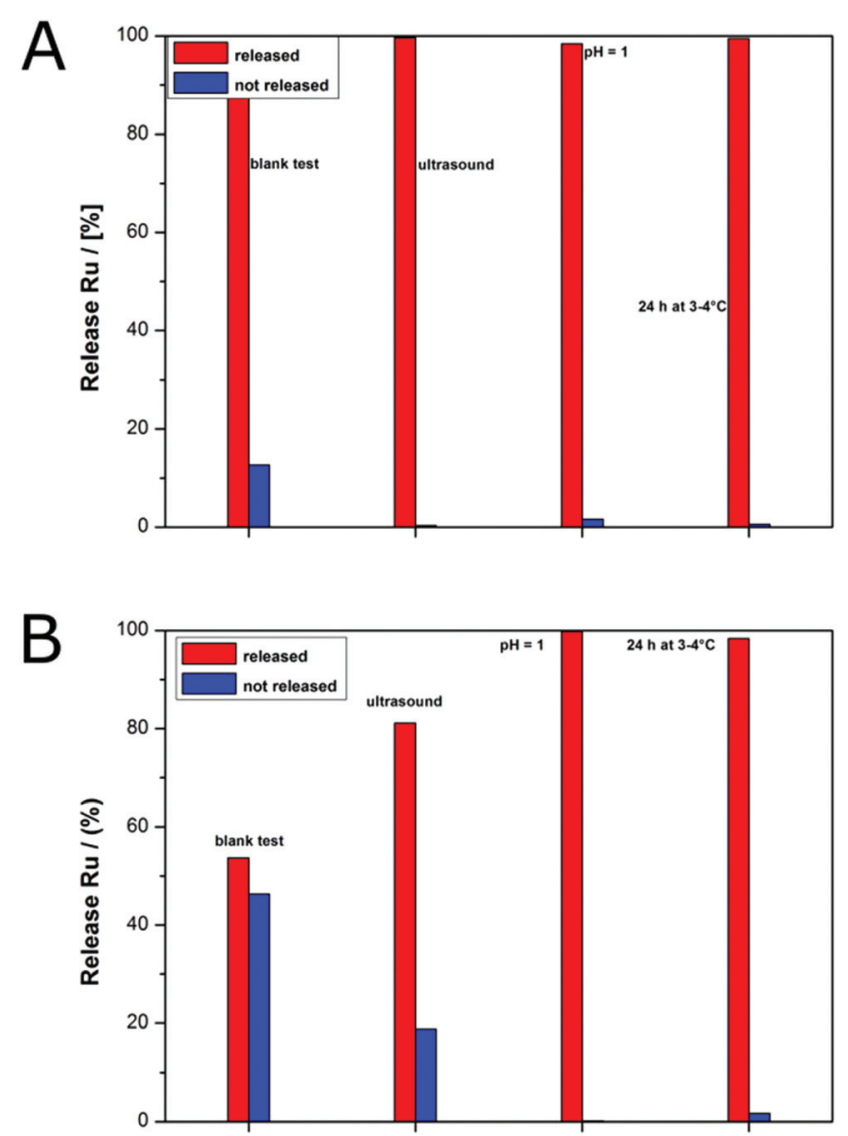

Fig. 7 Release profiles for BCP micelles loaded with Ru(II) complex 7 based on Copo2 (A) and Copo1 (B) by using ultrasound, $\mathrm{pH}$ value change or storage at $3{ }^{\circ} \mathrm{C}$ as external triggers (see the Experimental section). The amount of the released ruthenium was determined by AAS. occurred already at room temperature due to the more diluted chain segments. Compared to this, Copo1 features the second LCST at a lower temperature, i.e., at room temperature the core of the BCP micelle is collapsed hindering a significant release of the Ru(II) complex. Only by further decreasing the temperature below the LCST of Copo1, the statistical block segment PDMAEMA-co-PMMA is capable of releasing the payload. While lowering the temperature down to $3{ }^{\circ} \mathrm{C}$, lowering the $\mathrm{pH}$ value of the aqueous environment or by application of ultrasound, an almost full release of the encapsulated $\mathrm{Ru}$ (II) complex was found. The absolute values for the $\mathrm{Ru}(\mathrm{II})$ complex loading are compiled in Table S4 in the ESI† nicely reflecting the release capabilities of the herein investigated BCP micelles upon treatment with the external stimuli.

Compared to this, Copo1 with a lower amount of DMAEMA moieties in the copolymer segment revealed much less leakage of the BCP micelle and hence a significantly reduced amount of $\mathrm{Ru}(\mathrm{II})$ complex was released (Fig. 7B). BCP micelles based on Copo1 and after dialysis were subjected to ultrasound for $1 \mathrm{~h}$. As a result, a residual amount of about $20 \%$ of the initial $\mathrm{Ru}$ (II) complex content was found, while about $80 \%$ could be released by ultrasound treatment. Micelles from the same batch loaded with exactly the same amount of $\mathrm{Ru}(\mathrm{II})$ complex showed an almost full release while changing the $\mathrm{pH}$ value to 1. Additionally, a full release of the payload could be accomplished by lowering the temperature down to $3^{\circ} \mathrm{C}$.

\section{Conclusions}

In the current work we present an efficient protocol for the preparation of $\operatorname{poly}(\mathrm{N}, \mathrm{N}$-dimethylaminoethyl methacrylate $)$ (PDMAEMA) based multi-stimuli responsive block copolymers (BCPs) with poly(methyl methacrylate) (PMMA) via anionic polymerization protocols. The block copolymers were capable of micellation in water and used for the incorporation of a $\mathrm{Ru}(\mathrm{II})$ polypyridyl complex, i.e., [Ru(bipy) $)_{2}$-dppz-7hydroxymethyl $]\left[\mathrm{PF}_{6}\right]_{2}$, which was previously shown to act as a potential photosensitizer in photodynamic therapy. The hydrophobic block segment was built by copolymerizing MMA with DMAEMA in order to enhance the Ru(II) complex release properties and to tailor the lower critical solution temperature (LCST) of the micelles. The thermo-responsiveness of the prepared BCP micelles and single polymer chains was investigated by temperature-dependent dynamic light scattering (DLS) experiments. These experiments revealed an increase of the hydrodynamic radii of the BCP micelles below a temperature of $25-30{ }^{\circ} \mathrm{C}$. While loaded micelles derived from PMMA- $b$ PDMAEMA showed an excellent shielding effect upon ultrasound, i.e., no ruthenium release was accomplished, a good switchability for $\left(\mathrm{PMMA}_{19}\right.$-co-PDMAEMA 22$)$ - $b$-PDMAEMA 191 (Copo1) was observed. This strong shielding effect of BCPs featuring a pure PMMA segment was attributed to the distinct core/shell structure of the loaded BCP micelles compared to more homogeneous BCP micelles as shown by TEM investigations. The latter micelles feature the capability to efficiently 
release the $\mathrm{Ru}(\mathrm{II})$ complex upon ultrasound, by lowering the $\mathrm{pH}$ value, and by decreasing the temperature as determined and quantified by atomic absorption spectrometry (AAS) after applying external triggers and dialysis. This study will pave the way to addressable and highly functional polymer-based nanocarrier systems with unprecedented properties that are stable and can be employed in water. Potential applications are foreseen in a variety of disciplines, in particular in biomedicine and smart delivery systems.

\section{Experimental}

\section{Reagents}

All solvents and reagents were purchased from Alfa Aesar, Sigma Aldrich, Fisher Scientific, ABCR and used as received unless stated otherwise. Deuterated solvents were additionally purchased from Deutero $\mathrm{GmbH}$, Kastellaun, Germany. Tetrahydrofuran (THF) was distilled from sodium/benzophenone under reduced pressure (cryo-transfer) prior to the addition of 1,1-diphenylethylene and $n$-butyllithium ( $n$-BuLi) followed by a second cryo-transfer. MMA and DMAEMA were first dried by stirring over calcium hydride $\left(\mathrm{CaH}_{2}\right)$, distilled, followed by drying over trioctylaluminium and a second cryotransfer prior to use. Lithium chloride ( $\mathrm{LiCl}$ ) was dissolved in a small amount of purified THF and placed into an ampule. After removing THF in a vacuum, the ampule was carefully heated out under high vacuum, refilled with nitrogen, and then stored in a glovebox. All syntheses were carried out under an atmosphere of nitrogen using Schlenk techniques or a glovebox equipped with a Coldwell apparatus. The $\mathrm{Ru}(\mathrm{II})$ complex was synthesized as reported previously. ${ }^{47}$

\section{Instrumentation}

NMR spectra were recorded with a Bruker DRX 500 NMR or with a Bruker DRX 300 spectrometer working at $500 \mathrm{MHz}$ or $300 \mathrm{MHz}\left({ }^{1} \mathrm{H}\right.$ NMR). NMR chemical shifts are referenced relative to tetramethylsilane. SEC measurements were performed with DMF as the mobile phase (flow rate $1 \mathrm{~mL} \mathrm{~min}^{-1}$ ) on a GRAM column set from PSS (GRAM 30, GRAM 1000, GRAM $1000)$ at $50{ }^{\circ} \mathrm{C}$. Calibration was carried out using PMMA standards (from Polymer Standard Service, Mainz).

For determining the thermal properties of the polymers differential scanning calorimetry (DSC) was performed with a Mettler Toledo DSC- 1 in the temperature range from $0{ }^{\circ} \mathrm{C}$ to $140{ }^{\circ} \mathrm{C}$ with a heating rate of $10 \mathrm{~K} \mathrm{~min}^{-1}$. TEM experiments were carried out on a Zeiss EM 10 electron microscope operating at $60 \mathrm{kV}$. All shown images were recorded with a slow-scan CCD camera obtained from TRS (Tröndle) in bright field mode. Camera control was computer-aided using the ImageSP software from TRS. Dynamic light scattering (DLS) experiments were carried out with a setup based on a He-Ne laser $(\lambda=$ $632.8 \mathrm{~nm}$ ) as the light source at different temperatures. Polarization of the primary beam is determined by using a Glan-Thomson prism. The scattered beam polarization is analyzed in vertical-vertical geometry. The scattered intensity was detected with an optical fiber coupled to two avalanche photodiodes. The intensity autocorrelation functions, calculated with ALV 5000 software for both photodiodes, were measured in angular steps of $10^{\circ}$. All measurements were performed by using cylindrical cuvettes (Hellma) for the samples in a temperature-controlled index matching bath. The correlation time $\tau$ is related to the translational diffusion coefficient $D$ and the scattering vector $q$ as $D=1 /\left(\tau q^{2}\right)$. The expected linear variation of $1 / \tau$ with $q^{2}$ is very nicely fulfilled by our data. By using the Stokes-Einstein relation, a hydrodynamic radius $R_{\mathrm{h}}=k_{\mathrm{B}} T / 6 \eta \pi D$ can be calculated, with $k_{\mathrm{B}}, T$, and $\eta$ as the Boltzmann constant, absolute temperature, and solvent viscosity. Dialysis experiments were performed using dialysis membranes (Spectra/Por® Biotech CE) against an excess of water $(1500 \mathrm{~mL}$ for approx. $6 \mathrm{~mL}$ of Ru-loaded block copolymer micelles). After 24 hours the water is changed, which is repeated overall three times.

For ultrasound experiments, a Hielscher UP50H operating at $30 \mathrm{kHz}$ and $50 \mathrm{~W}$ equipped with a Hielscher MS1 titanium sonotrode was used while cooling the samples. For determining the Ru content, atomic absorption spectrometry (AAS) was performed. For additional DLS and zetapotential measurements a Zetasizer Nano ZS90 equipped with a $4 \mathrm{~mW} 633 \mathrm{~nm}$ He-Ne laser was used.

For AAS measurements a contrAA 700 high-resolution continuum-source atomic absorption spectrometer (Analytik Jena AG) was used. Pure samples of the respective complex were used for preparing the standards and calibration was done in a matrix-matched manner (meaning all samples and standards were adjusted to the same polymer concentration by dilution with distilled water if necessary). Triton-X $100(1 \%, 10 \mu \mathrm{L})$ as well as nitric acid $(13 \%, 10 \mu \mathrm{L})$ were added to all probes $(100 \mu \mathrm{L})$ as modifiers. The samples were injected $(25 \mu \mathrm{L})$ into coated standard graphite tubes (Analytik Jena AG) and thermally processed as previously described in more detail. ${ }^{64} \mathrm{Ru}$ was quantified at a wavelength of $349.90 \mathrm{~nm} .{ }^{65}$ The mean integrated absorbances of triplicate injections were used throughout the study.

\section{Anionic block copolymerization of methyl methacrylate and $\mathrm{N}, \mathrm{N}$-dimethylaminoethyl methacrylate}

Exemplary synthesis of $\left(\right.$ PMMA $_{19}$-co-PDMAEMA $\left.{ }_{22}\right)-b$ PDMAEMA $_{\text {191 }}$. In an ampule equipped with a stirring bar $13 \mathrm{mg} \mathrm{LiCl}$ (0.3 mmol, 10 eq.), $87 \mathrm{mg}$ MMA (0.87 mmol, 27 eq.) and $223 \mathrm{mg}$ DMAEMA ( $1.4 \mathrm{mmol}, 44$ eq.) are dissolved in $30 \mathrm{~mL}$ THF. The solution is cooled to $-78^{\circ} \mathrm{C}$. The polymerization is started by quickly adding DPHLi solution, which is prepared by mixing $11.5 \mu \mathrm{L}$ DPE (0.06, 2 eq.) and $20 \mu \mathrm{L} n$-BuLi (1.6 $\mathrm{M}$ in hexane, $0.03 \mathrm{mmol}, 1 \mathrm{eq}$.) in $1 \mathrm{~mL}$ THF. After $1 \mathrm{~h}$, an aliquot of the solution is taken from the ampule for characterization of the PMMA-co-PDMAEMA segment and terminated by adding methanol. Then, $1600 \mathrm{mg}$ DMAEMA $(10.2 \mathrm{mmol}$, 318 eq.) is added to the active macro-anions. After $1 \mathrm{~h}$ of reaction time, $0.1 \mathrm{~mL}$ methanol is added to terminate the polymerization. The polymer solution is added to $250 \mathrm{~mL}$ water and stirred at $70{ }^{\circ} \mathrm{C}$ to precipitate the polymer. The polymer is 
collected by filtration and dried in vacuo. Yield: $1.50 \mathrm{~g}(85 \%)$. The first block segment features $46 \mathrm{~mol} \% \mathrm{MMA}$ as determined by ${ }^{1} \mathrm{H}$ NMR spectroscopy.

SEC: $\mathrm{PMMA}_{19}-$ Co-PDMAEMA 22 :

$M_{\mathrm{n}}=5400 \mathrm{~g} \mathrm{~mol}^{-1} ; M_{\mathrm{w}}=6000 \mathrm{~g} \mathrm{~mol}^{-1} ; Ð=1.11$.

$\left(\right.$ PMMA $_{19}$-Co-PDMAEMA 22$)$ - $b$-PDMAEMA 191 :

$M_{\mathrm{n}}=31800 \mathrm{~g} \mathrm{~mol}^{-1} ; M_{\mathrm{w}}=35800 \mathrm{~g} \mathrm{~mol}^{-1} ; Ð=1.13$.

${ }^{1} \mathbf{H}$-NMR (300 MHz, $\left.\mathrm{CDCl}_{3}, 300 \mathrm{~K}\right): \delta=0.90-1.05\left(\mathrm{~m}, \mathrm{H}_{2,5}\right)$; 1.81-2.01 (m, $\left.\mathrm{H}_{1,4}\right) ; 2.28\left(\mathrm{~m}, \mathrm{H}_{8}\right) ; 2.55\left(\mathrm{~m}, \mathrm{H}_{7}\right) ; 3.58\left(\mathrm{~m}, \mathrm{H}_{3}\right)$; $4.05\left(\mathrm{~m}, \mathrm{H}_{6}\right) \mathrm{ppm}$.

Exemplary synthesis of (PMMA 13 -co-PDMAEMA 22$)-b$ PDMAEMA $_{132}$. In an ampule equipped with a stirring bar $13 \mathrm{mg}$ LiCl (0.3 mmol, 10 eq.), $76 \mathrm{mg}$ MMA (0.76 mmol, 24 eq.) and $239 \mathrm{mg}$ DMAEMA (1.5 mmol, 47 eq.) are dissolved in $30 \mathrm{~mL}$ THF. The solution is cooled to $-78^{\circ} \mathrm{C}$. The polymerization is started by quickly adding DPHLi solution, which is prepared by mixing $11.5 \mu \mathrm{L}$ DPE (0.06, 2 eq.) and $20 \mu \mathrm{L} n$-BuLi (1.6 $\mathrm{M}$ in hexane, $0.03 \mathrm{mmol}, 1$ eq.) in $1 \mathrm{~mL}$ THF. After $1 \mathrm{~h}$ of reaction time, an aliquot of the solution is taken from the ampule for characterization of the PMMA-co-PDMAEMA segment and terminated by adding methanol. Then, $1600 \mathrm{mg}$ DMAEMA (10.2 mmol, 318 eq.) is added to the macro-anions. After $1 \mathrm{~h}$ of reaction time, $0.1 \mathrm{~mL}$ methanol is added to terminate the polymerization. The polymer solution is added to $250 \mathrm{~mL}$ water stirred at $70{ }^{\circ} \mathrm{C}$ to precipitate the polymer. The polymer is collected by filtration and dried in vacuo. Yield: $1.58 \mathrm{~g}(86 \%)$.

SEC: PMMA $_{13}-$ Co-PDMAEMA 22 :

$M_{\mathrm{n}}=4700 \mathrm{~g} \mathrm{~mol}{ }^{-1} ; M_{\mathrm{w}}=5300 \mathrm{~g} \mathrm{~mol}^{-1} ; Ð=1.11$.

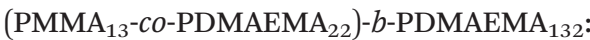

$M_{\mathrm{n}}=26900 \mathrm{~g} \mathrm{~mol}^{-1} ; M_{\mathrm{W}}=29600 \mathrm{~g} \mathrm{~mol}^{-1} ; D=1.10$.

${ }^{1}$ H-NMR (300 MHz, $\left.\mathrm{CDCl}_{3}, 300 \mathrm{~K}\right): \delta=0.90-1.05$ (m, H2,5); 1.82-1.98 (m, H1,4); 2.28 (m, H8); 2.56 (m, H7); 3.58 (m, H3); 4.05 (m, H6) ppm.

TEM sample preparation for (PMMA-co-PDMAEMA)- $b$ PDMAEMA and micelle loading with $\left[\mathrm{Ru}(\mathrm{bipy})_{2}\right.$-dppz-7hydroxymethyl $]\left[\mathrm{PF}_{6}\right]_{2}$

The corresponding PMMA-co-PDMAEMA- $b$-PDMAEMA samples (50 mg) are dissolved in filtered (0.45 $\mu \mathrm{m}$ cut-off) acetone $(0.5 \mathrm{~mL})$ and water ( $5 \mathrm{~mL}$, Milli-Q water) is added dropwise during constant and moderate stirring. For TEM investigations, the micellar solution is diluted with the 10 -fold volume of filtered water and the solution is drop-cast on a carbon-coated copper grid, followed by drying under ambient conditions. For block copolymer micelle loading, the corresponding PMMA-co-PDMAEMA- $b$-PDMAEMA samples (50 mg) and $\left[\mathrm{Ru}(\text { bipy })_{2}\right.$-dppz-7-hydroxymethyl $]\left[\mathrm{PF}_{6}\right]_{2}(5 \mathrm{mg})$ are dissolved in filtered acetone $(1 \mathrm{~mL})$. In the next step, water $(5 \mathrm{~mL})$ is added dropwise during moderate stirring. An orange and stable solution is obtained. For TEM investigations, the micellar solution is diluted with the 10-fold volume of filtered water and the resulting solution is drop-cast on a carbon-coated copper grid, followed by drying under ambient conditions.

\section{Ruthenium release from (PDMAEMA-co-PMMA)- $b$-PDMAEMA} micelles by external triggers

Temperature. The micellar block copolymer solution $(1 \mathrm{~mL})$ containing $\left[\mathrm{Ru}(\text { bipy })_{2}\right.$-dppz-7-hydroxymethyl $]\left[\mathrm{PF}_{6}\right]_{2}$ is cooled at $3{ }^{\circ} \mathrm{C}$ for 24 hours before dialyzing (dialysis membranes: Spectra/Por ${ }^{\circledR}$ Biotech $\left.\mathrm{CE}\right)$ against water $(300 \mathrm{~mL})$ for 3 days. The aqueous phase and the volume of the dialysis membrane are evaporated and the residue is characterized by atomic absorption spectrometry (AAS).

pH variation. The micellar block copolymer solution (1 mL) containing [Ru(bipy) $)_{2}$-dppz-7-hydroxymethyl $]\left[\mathrm{PF}_{6}\right]_{2}$ is acidified with $\mathrm{HCl}$ to a pH value of 1 before it is dialyzed (dialysis membranes: Spectra/Por ${ }^{\circledR}$ Biotech CE) against water $(300 \mathrm{~mL})$ for 3 days. The aqueous phase and the volume of the dialysis membrane are evaporated and the residue is characterized by atomic absorption spectrometry (AAS).

Ultrasound. The micellar block copolymer solution $(1 \mathrm{~mL})$ containing $\left[\mathrm{Ru}(\text { bipy })_{2}\right.$-dppz-7-hydroxymethyl $]\left[\mathrm{PF}_{6}\right]_{2}$ is sonicated for 1 hour before dialysis (dialysis membranes: Spectra/ Por ${ }^{\circledR}$ Biotech $\left.\mathrm{CE}\right)$ against water $(300 \mathrm{~mL})$ for 3 days. The aqueous phase and the volume of the dialysis membrane are evaporated and the residue is characterized by atomic absorption spectrometry (AAS).

Blank samples. The micellar block copolymer solution (1 mL) containing $\left[\mathrm{Ru}(\text { bipy })_{2}\right.$-dppz-7-hydroxymethyl $]\left[\mathrm{PF}_{6}\right]_{2}$ is dialyzed (dialysis membranes: Spectra/Por ${ }^{\circledR}$ Biotech CE) against water $(300 \mathrm{~mL})$ for 3 days. The aqueous phase and the volume of the dialysis membrane are evaporated and the residue is characterized by atomic absorption spectrometry (AAS).

\section{Acknowledgements}

The authors thank Christian Rüttiger for additional TEM images. M. G. thanks the Fonds der Chemischen Industrie (FCI) for financial support of this work. M. G. and M. A. acknowledge the German Research Foundation (DFG GA 2169/1-1). This work has been additionally supported in the frame of the LOEWE project iNAPO by the Hessen State Ministry of Higher Education, Research and the Arts and in the frame of the Smart Inorganic Polymer EU network (COST CM10302, SIPS). J. E. would like to thank the German Academic Exchange Service (DAAD) for a Postdoctoral fellowship. G. G. thanks the Swiss National Science Foundation (Professorships No. PP00P2_133568 and PP00P2_157545), the University of Zurich and the Stiftung für wissenschaftliche Forschung of the University of Zurich (G. G). This work has received support under the program "Investissements d'Avenir" launched by the French Government and implemented by the ANR with the reference ANR-10-IDEX-0001-02 PSL (G. G.). C. M. thanks the Forschungskredit of the University of Zurich (Grant K-7353201-01). 


\section{References}

1 M. A. C. Stuart, W. T. S. Huck, J. Genzer, M. Müller, C. Ober, M. Stamm, G. B. Sukhorukov, I. Szleifer, V. V. Tsukruk, M. Urban, F. Winnik, S. Zauscher, I. Luzinov and S. Minko, Nature, 2010, 9, 101-113.

2 F. Liu and M. W. Urban, Prog. Polym. Sci., 2010, 35, 3-23.

3 D. Roy, J. N. Cambre and B. S. Sumerlin, Prog. Polym. Sci., 2010, 35, 278-301.

4 A. E. Smith, X. Xu and C. L. McCormick, Prog. Polym. Sci., 2010, 35, 45-93.

5 F. H. Schacher, P. A. Rupar and I. Manners, Angew. Chem., Int. Ed., 2012, 51, 7898-7921.

6 J. I. Clodt, V. Filiz, S. Rangou, K. Buhr, C. Abetz, D. Höche, J. Hahn, A. Jung and V. Abetz, Adv. Funct. Mater., 2013, 23, 731-738.

7 M. Gallei, S. Rangou, V. Filiz, K. Buhr, S. Bolmer, C. Abetz and V. Abetz, Macromol. Chem. Phys., 2013, 214, 1037-1046.

8 C. G. Schäfer, M. Gallei, J. T. Zahn, J. Engelhardt, G. P. Hellmann and M. Rehahn, Chem. Mater., 2013, 25, 2309-2318.

9 C. G. Schäfer, C. Lederle, K. Zentel, B. Stühn and M. Gallei, Macromol. Rapid Commun., 2014, 35, 1852-1860.

10 C. Rüttiger, V. Pfeifer, V. Rittscher, D. Stock, D. Scheid, S. Vowinkel, F. Roth, H. Didzoleit, B. Stühn, J. Elbert, E. Ionescu and M. Gallei, Polym. Chem., 2016, 7, 1129-1137.

11 R. H. Staff, M. Gallei, K. Landfester and D. Crespy, Macromolecules, 2014, 47, 4876-4883.

12 Y. Bae, S. Fukushima, A. Harada and K. Kataoka, Angew. Chem., Int. Ed., 2003, 42, 4640-4643.

13 R. Haag, Angew. Chem., Int. Ed., 2004, 43, 278-282.

14 C. de Las Heras Alarcon, S. Pennadam and C. Alexander, Chem. Soc. Rev., 2005, 34, 276-285.

15 D. G. Shchukin and H. Möhwald, Science, 2013, 341, 14581459.

16 L. P. Lv, Y. Zhao, N. Vilbrandt, M. Gallei, A. Vimalanandan, M. Rohwerder, K. Landfester and D. Crespy, J. Am. Chem. Soc., 2013, 135, 14198-14205.

17 M. Marguet, L. Edembe and S. Lecommandoux, Angew. Chem., Int. Ed., 2012, 51, 1173-1176.

18 Y. Zhao, L.-P. Lv, S. Jiang, K. Landfester and D. Crespy, Polym. Chem., 2015, 6, 4197-4205.

19 X. Huang and B. Voit, Polym. Chem., 2013, 4, 435-443.

20 R. H. Staff, M. Gallei, M. Mazurowski, M. Rehahn, R. Berger, K. Landfester and D. Crespy, ACS Nano, 2012, 6, 9042-9049.

21 S. Kubowicz, J. F. Baussard, J. F. Lutz, A. F. Thunemann, H. von Berlepsch and A. Laschewsky, Angew. Chem., Int. Ed., 2005, 44, 5262-5265.

22 A. H. Gröschel, A. Walther, T. I. Löbling, F. H. Schacher, H. Schmalz and A. H. Muller, Nature, 2013, 503, 247-251.

23 T. I. Löbling, O. Borisov, J. S. Haataja, O. Ikkala, A. H. Gröschel and A. H. Müller, Nat. Commun., 2016, 7, 12097.

24 S. Behzadi, M. Gallei, J. Elbert, M. Appold, G. Glasser, K. Landfester and D. Crespy, Polym. Chem., 2016, 7, 34343443 .
25 T. P. Lodge, A. Rasdal, Z. Li and M. A. Hillmyer, J. Am. Chem. Soc., 2005, 127, 17608-17609.

26 F. L. Baines, N. C. Billingham and S. P. Armes, Macromolecules, 1996, 29, 3416-3420.

27 W. Xu, A. A. Steinschulte, F. A. Plamper, V. F. Korolovych and V. V. Tsukruk, Chem. Mater., 2016, 28, 975-985.

28 T. Thavanesan, C. Herbert and F. A. Plamper, Langmuir, 2014, 30, 5609-5619.

29 Y. Zhou, Principles and Applications of Therapeutic Ultrasound in Healthcare, CRC Press Taylor and Francis Group, Boca Raton, USA, 2016.

30 G. A. Husseini, D. A. Christensen, N. Y. Rapoport and W. G. Pitta, J. Controlled Release, 2002, 83, 303-305.

31 A. Marin, M. Muniruzzaman and N. Rapoport, J. Controlled Release, 2001, 75, 69-81.

32 S. Agarwal, Y. Zhang, S. Maji and A. Greiner, Mater. Today, 2012, 15, 388-393.

33 U. Rungsardthong, M. Deshpande, L. Bailey, M. Vamvakaki, S. P. Armes, M. C. Garnett and S. Stolnik, J. Controlled Release, 2001, 73, 359-380.

34 P. V. D. Wetering, J.-Y. Cherng, H. Talsma, D. J. A. Crommelin and W. E. Hennink, J. Controlled Release, 1998, 53, 145-153.

35 I. Tabujew and K. Peneva, Functionalization of Cationic Polymers for Drug Delivery Applications, RSC Polymer Chemistry Series, 2014.

36 D. E. J. G. J. Dolmans, D. Fukumura and R. K. Jain, Nat. Rev. Cancer, 2003, 3, 380-387.

37 C. Mari, V. Pierroz, S. Ferrari and G. Gasser, Chem. Sci., 2015, 6, 2660-2686.

38 A. P. Castano, T. N. Demidova and M. R. Hamblin, Photodiagn. Photodyn. Ther., 2004, 1, 279-293.

39 F. S. De Rosa and M. V. L. B. Bentley, Pharm. Res., 2000, 17, 1447-1455.

40 T. Debele, S. Peng and H.-C. Tsai, Int. J. Mol. Sci., 2015, 16, 22094.

41 J. D. Knoll and C. Turro, Coord. Chem. Rev., 2015, 282-283, 110-126.

42 G. Shi, S. Monro, R. Hennigar, J. Colpitts, J. Fong, K. Kasimova, H. Yin, R. DeCoste, C. Spencer, L. Chamberlain, A. Mandel, L. Lilge and S. A. McFarland, Coord. Chem. Rev., 2015, 282-283, 127-138.

43 S. Bonnet, Comments Inorg. Chem., 2015, 35, 179-213.

44 B. S. Howerton, D. K. Heidary and E. C. Glazer, J. Am. Chem. Soc., 2012, 134, 8324-8327.

45 G. Li, L. Sun, L. Ji and H. Chao, Dalton Trans., 2016, 45, 13261-13276.

46 http:/www.stockhouse.com/news/press-releases/2015/01/ 15/theralase-identifies-lead-photo-dynamic-compound-forhuman-clinical-trials.

47 C. Mari, V. Pierroz, R. Rubbiani, M. Patra, J. Hess, B. Spingler, L. Oehninger, J. Schur, I. Ott, L. Salassa, S. Ferrari and G. Gasser, Chem. - Eur. J., 2014, 20, 14421-14436.

48 H. Huang, B. Yu, P. Zhang, J. Huang, Y. Chen, G. Gasser, L. Ji and H. Chao, Angew. Chem., Int. Ed., 2015, 54, 1404914052. 
49 V. Pierroz, R. Rubbiani, C. Gentili, M. Patra, C. Mari, G. Gasser and S. Ferrari, Chem. Sci., 2016, 7, 6115-6124.

50 A. Frei, R. Rubbiani, S. Tubafard, O. Blacque, P. Anstaett, A. Felgenträger, T. Maisch, L. Spiccia and G. Gasser, J. Med. Chem., 2014, 57, 7280-7292.

51 A. Leonidova, V. Pierroz, R. Rubbiani, Y. Lan, A. G. Schmitz, A. Kaech, R. K. O. Sigel, S. Ferrari and G. Gasser, Chem. Sci., 2014, 5, 4044-4056.

52 T. Joshi, V. Pierroz, C. Mari, L. Gemperle, S. Ferrari and G. Gasser, Angew. Chem., Int. Ed., 2014, 53, 2960-2963.

53 C. S. Jin and G. Zheng, Lasers Surg. Med., 2011, 43, 734-748.

54 E. Paszko, C. Ehrhardt, M. O. Senge, D. P. Kelleher and J. V. Reynolds, Photodiagn. Photodyn. Ther., 2011, 8, 14-29.

55 E. B. Gyenge, S. Hiestand, S. Graefe, H. Walt and C. Maake, Photodiagn. Photodyn. Ther., 2011, 8, 86-96.

56 J. Svensson, A. Johansson, S. Gräfe, B. Gitter, T. Trebst, N. Bendsoe, S. Andersson-Engels and K. Svanberg, Photochem. Photobiol., 2007, 83, 1211-1219.

57 G. Bœuf, G. V. Roullin, J. Moreau, L. Van Gulick, N. Zambrano Pineda, C. Terryn, D. Ploton, M. C. Andry,
F. Chuburu, S. Dukic, M. Molinari and G. Lemercier, ChemPlusChem, 2014, 79, 171-180.

58 A. Arce, F. Fornasiero, O. Rodríguez, C. J. Radke and J. M. Prausnitz, Phys. Chem. Chem. Phys., 2004, 6, 103-108.

59 M. Gallei, R. Klein and M. Rehahn, Macromolecules, 2010, 43, 1844-1854.

60 Y. Mai and A. Eisenberg, Chem. Soc. Rev., 2012, 41, 59695985.

61 J. Morsbach, J. Elbert, C. Rüttiger, S. Winzen, H. Frey and M. Gallei, Macromolecules, 2016, 49, 3406-3414.

62 J. Morsbach, A. Natalello, J. Elbert, S. Winzen, A. Kroeger, H. Frey and M. Gallei, Organometallics, 2013, 32, 60336039.

63 J. Kestin, M. Sokolov and W. W. Wakeham, J. Phys. Chem., 1978, 7, 941-948.

64 J. Skiba, C. Schmidt, P. Lippmann, P. Ensslen, H.-A. Wagenknecht, R. Czerwieniec, F. Bandl, I. Ott, T. Bernaś, B. Krawczyk, D. Szczukocki and K. Kowalski, Eur. J. Inorg. Chem., 2016, DOI: 10.1002/ejic.201600281.

65 S. Schäfer, I. Ott, R. Gust and W. S. Sheldrick, Eur. J. Inorg. Chem., 2007, 2007, 3034-3046. 